\title{
Crescimento de plantas micropropagadas de macieira em casa de vegetação com aplicações de ácido giberélico ${ }^{(1)}$
}

\author{
Jonny Everson Scherwinski Pereira ${ }^{(2)}$, Gerson Renan de Luces Fortes ${ }^{(3)}$ \\ e João Baptista da Silva(4)
}

\begin{abstract}
Resumo - O objetivo deste trabalho foi otimizar o crescimento de plantas micropropagadas do portaenxerto de macieira 'Marubakaido' (Malus prunifolia) em casa de vegetação, por meio da aplicação de ácido giberélico $\left(\mathrm{AG}_{3}\right)$ por uma, duas, ou três vezes, em intervalos semanais. As concentrações testadas foram: $0,50,100,200,400,800 \mathrm{e} 1.600 \mathrm{mg} \mathrm{L}^{-1}$. O crescimento das plantas foi avaliado quinzenalmente, por um período de dois meses. O comprimento dos entrenós e a matéria seca da parte aérea das plantas também foram avaliados no final do experimento. Três aplicações de $\mathrm{AG}_{3}$ na concentração de $800 \mathrm{mg} \mathrm{L}^{-1}$ foi o tratamento que proporcionou a maior taxa de crescimento das plantas $(912 \%$ contra $114 \%$ das plantas não-tratadas), além de proporcionar plantas com maior comprimento de entrenós e massa seca da parte aérea. Plantas pulverizadas uma única vez não apresentaram diferenças significativas em nenhuma das variáveis estudadas. Estes resultados sugerem que o uso do $\mathrm{AG}_{3}$ em plantas de macieira, oriundas da micropropagação, melhora o crescimento, embora um número de pelo menos três aplicações, associado com concentrações mais elevadas, seja necessário para melhorar a eficiência deste regulador.
\end{abstract}

Termos para indexação: Malus prunifolia, cultura in vitro, adaptação, dormência.

\section{Growth of micropropagated apple plants in greenhouse with gibberellic acid applications}

\begin{abstract}
Aiming to optimize plant growth of the apple rootstock cultivar Marubakaido (Malus prunifolia) in greenhouse, one-year old plants coming from in vitro cultivation were sprayed once, twice and three times in a 7-day interval with gibberellic acid $\left(\mathrm{GA}_{3}\right)$. The concentrations of $0,50,100$, $200,400,800$ and $1,600 \mathrm{mg} \mathrm{L}^{-1}$ were used. Plant growth was evaluated every two weeks during two months. Internode length, number of buds and the dry mass of the aerial part were also evaluated at the end of the experiment. Three sprays of $\mathrm{GA}_{3}$ at $800 \mathrm{mg} \mathrm{L}^{-1}$ was the best treatment providing the largest rate of plant growth ( $912 \%$ against $114 \%$ of non-treated plants) in relation to their initial height, besides providing larger internode length and higher dry matter of aerial parts. Plants sprayed once did not present significant response to $\mathrm{GA}_{3}$ for none of the studied variables. These results suggest that the use of $\mathrm{GA}_{3}$, in apple plants coming from micropropagation, improves the growth, although a number of at least three applications, associated with high concentrations, is necessary to improve the efficiency of this regulator.
\end{abstract}

Index terms: Malus prunifolia, in vitro culture, adaptation, dormancy.

(1) Aceito para publicação em 16 de agosto de 2000 .

(2) Universidade Federal de Pelotas (UFPel), Faculdade de Agronomia Eliseu Maciel (FAEM), Caixa Postal 354, CEP 96001-970 Pelotas, RS. E-mail: jscherwi@ufpel.tche.br

(3)Embrapa-Centro de Pesquisa Agropecuária de Clima Temperado (CPACT), Caixa Postal 403, CEP 96001-970 Pelotas, RS. E-mail: gerson@cpact.embrapa.br

(4)UFPel, Instituto de Física e Matemática.

E-mail: jbsilva@ufpel.tche.br

\section{Introdução}

As mudas de macieira são obtidas normalmente através da enxertia de uma cultivar copa sobre determinado porta-enxerto. O processo de produção dos porta-enxertos usado tradicionalmente é o da mergulhia de cepa, demandando muito tempo, mãode-obra e considerável espaço físico, além de possibilitar a propagação de material vegetativo com pro- 
blemas fitossanitários (Barbosa et al., 1986; Denardi \& Leite, 1996). Porém, estes problemas podem ser superados mediante a propagação in vitro. Essa técnica é uma alternativa para a minimização destes problemas, pois possibilita a rápida propagação de porta-enxertos e cultivares sadios (Zimmerman \& Fordham, 1985; Debergh, 1988).

Em virtude das condições de cultivo in vitro (ambiente asséptico, umidade relativa elevada, iluminação pouco intensa, trocas gasosas limitadas, temperatura e fotoperíodo controlados), quando as plântulas são aclimatizadas, estas ficam sujeitas a forte estresse, decorrente das mudanças ambientais sofridas, podendo, em muitos casos, ocorrer sua morte (Preece \& Sutter, 1991; Huylenbroeck \& Debergh, 1996). Especificamente em macieira, as plantas, quando aclimatizadas, apresentam uma parada no crescimento vegetativo, normalmente até a estação seguinte de crescimento, podendo ser caracterizada como um tipo de dormência (Ribas \& Zanette, 1992; Pereira, 1999). Aplicações de giberelinas são freqüentemente eficazes para a superação da dormência e retorno ao crescimento das plantas (Champagnat, 1992; Kavanagh et al., 1993). De todos os reguladores de crescimento, as giberelinas são as que mostram os maiores efeitos quando aplicadas em plantas intactas. São consideradas, as giberelinas, substâncias promotoras do crescimento que produzem grande efeito em plantas, especialmente no alongamento dos entrenós (Metivier, 1985; Huttly \& Phillips, 1995). Contudo, também apresentam um papel chave na quebra da dormência das plantas. Gianfagna (1987) afirma que o ácido giberélico pode ser usado para quebrar a dormência das plantas que não tenham recebido um período de frio adequado para retornar ao crescimento. Shaltout \& Unrath (1983) relatam que aplicações de giberelinas podem, em alguns casos, estimular a saída da dormência, sem contudo eliminar inteiramente as necessidades de frio, sendo mais efetivas no final do processo. Powell (1987) cita que aplicações de giberelinas, na maioria das espécies, evidenciam sua importância para o crescimento das plantas, embora uma única aplicação nem sempre seja suficiente. Entretanto, um fornecimento contínuo, promove um crescimento substancial. Para Tomlinson et al. (1985), a diminuição nas concentrações endógenas de giberelinas nas plantas provoca a pa- rada no alongamento e, conseqüentemente, no crescimento dos ápices vegetativos. Pelo fato de estes locais apresentarem baixas concentrações em giberelinas quando dormentes, aplicações de giberelinas são freqüentemente eficazes para a superação da dormência e permitem que a planta retorne ao crescimento.

Este trabalho teve como objetivo avaliar o efeito do número de aplicações e de diferentes concentrações de ácido giberélico sobre o crescimento de plantas do porta-enxerto de macieira 'Marubakaido' dormentes, de um ano, oriundas da micropropagação, em casa de vegetação.

\section{Material e Métodos}

O trabalho foi desenvolvido na Embrapa-Centro Nacional de Pesquisa Agropecuária de Clima Temperado, em Pelotas, RS, entre os meses de setembro e dezembro de 1998. Plantas micropropagadas do porta-enxerto de macieira 'Marubakaido' (Malus prunifolia Borkh.), de um ano, em estado dormente, haste única e tamanho médio de $2,8 \mathrm{~cm}$, compreendido entre a região do colo e a inserção da última folha, que estavam acondicionadas em bandejas de semeadura contendo uma mistura de terra de mato e vermiculita $(3: 1 \mathrm{v} / \mathrm{v})$, foram transferidas do telado para casa de vegetação, onde o número de aplicações e diferentes concentrações de $\mathrm{AG}_{3}$ foram testados. Durante o tempo de permanência das plantas no telado, foram registradas 129 horas de frio incidentes sobre as plantas durante o inverno. Este número foi obtido relacionando-se o número de horas que ocorreu temperatura igual ou inferior à temperatura-base de $7,2^{\circ} \mathrm{C}$.

Os tratamentos consistiram de uma, duas e três aplicações de $\mathrm{AG}_{3}$ nas concentrações de 0 (controle), 50, 100, 200, 400, 800 e $1.600 \mathrm{mg} \mathrm{L}^{-1}$. Plantas tratadas por mais de uma vez receberam pulverizações semanais. Em todos os tratamentos, o surfactante Tween-20, na concentração de $0,1 \%(\mathrm{v} / \mathrm{v})$, foi adicionado à solução de $\mathrm{AG}_{3}$. As pulverizações foram realizadas pela manhã, com o auxílio de um pulverizador manual portátil.

Avaliou-se, quinzenalmente, o crescimento das plantas, compreendido entre a região do colo e a inserção da última folha, por um período de 60 dias. Ao final deste período, avaliaram-se, ainda, o número e comprimento dos entrenós e o peso da matéria seca da parte aérea das plantas.

O delineamento experimental utilizado foi o de blocos casualizados, com cinco repetições, e cada repetição formada por cinco plantas. Os resultados obtidos foram analisados estatisticamente, com o auxílio do programa SANEST (Zonta \& Machado, 1984). 


\section{Resultados e Discussão}

Embora as plantas utilizadas neste experimento, provenientes do viveiro, estivessem em estado dormente, após 15 dias de permanência em casa de vegetação e temperatura média de $25 \pm 3^{\circ} \mathrm{C}$, todas elas apresentavam a gema terminal em estado de gema aberta (Ribas, 1991), inclusive as plantas não-tratadas (controle). Este fato indica que as baixas temperaturas ocorridas no inverno (129 horas abaixo de $7,2^{\circ} \mathrm{C}$ ), incidentes sobre estas plantas ainda no viveiro, associadas às temperaturas mais elevadas quando transferidas para a casa de vegetação, foram suficientes para promover a superação da dormência destas gemas. Porém, as gemas axilares continuaram em estado dormente. Segundo Champagnat (1992), a necessidade de frio para superar a dormência varia, entre outros fatores, com a localização da gema na planta, pois as gemas vegetativas laterais, em geral, requerem maior quantidade de frio do que as terminais. Além disso, ramos curtos exigem menos frio do que ramos longos.

As avaliações do tamanho da planta no estágio inicial e aos 60 dias, após receberem diferentes concentrações de $\mathrm{AG}_{3}$ em uma, duas ou três aplicações, são apresentadas na Figura 1. Na avaliação inicial, pode ser observado o tamanho das plantas utilizadas nos diferentes tratamentos. Verifica-se que estas não apresentavam diferenças significativas de tamanho $(\mathrm{p} \leq 0,05)$, dentro de cada concentração, com exceção das plantas selecionadas para receberem $400 \mathrm{e}$ $800 \mathrm{mg} \mathrm{L}^{-1}$ de $\mathrm{AG}_{3}$. Nestes tratamentos, as plantas escolhidas para receberem três pulverizações, apresentavam um tamanho significativamente menor do que as que iriam receber uma ou duas aplicações. Essas diferenças foram decorrentes da dificuldade de obter plantas de tamanho homogêneo para compor o experimento.

A avaliação do tamanho das plantas após 60 dias do início do experimento revelou que as plantas tratadas com diferentes concentrações de $\mathrm{AG}_{3}$ atingiram maior tamanho quando receberam, de modo geral, três aplicações, em concentrações superiores a $200 \mathrm{mg} \mathrm{L}^{-1}$ (Figura 1).

Nas plantas que receberam uma aplicação, nenhuma regressão mostrou-se significativa (Figura 2). Plantas que receberam duas aplicações mostraram um comportamento linear crescente na porcentagem de crescimento das plantas, em relação ao seu tamanho inicial, com o aumento nas concentrações de $\mathrm{AG}_{3}$. Já a curva referente à porcentagem final de crescimento de plantas que receberam três aplicações de $\mathrm{AG}_{3}$ mostrou um efeito quadrático em relação às concentrações; ascendente, até um ponto máximo atingido em $1.116 \mathrm{mg} \mathrm{L}^{-1} \mathrm{de}_{\mathrm{AG}_{3}}$, quando a maior

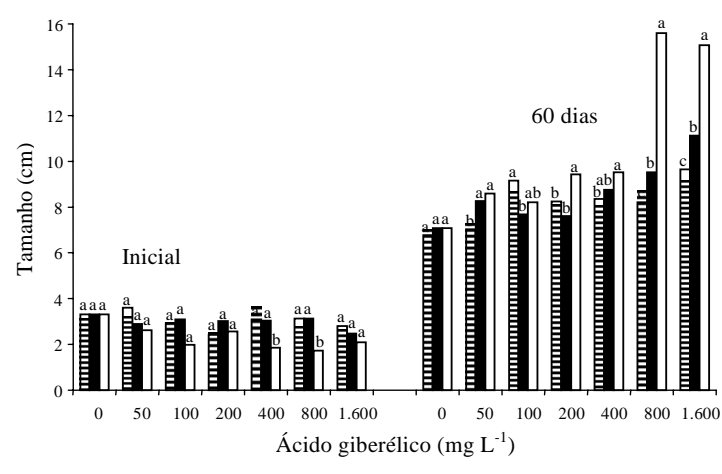

Figura 1. Tamanho das plantas do porta-enxerto de macieira Marubakaido, no estádio inicial e aos 60 dias após receberem diferentes concentrações de ácido giberélico em uma $(\Theta)$, duas $(\mathbf{\square})$ ou três $(\square)$ aplicações. Embrapa-CPACT, Pelotas, RS.

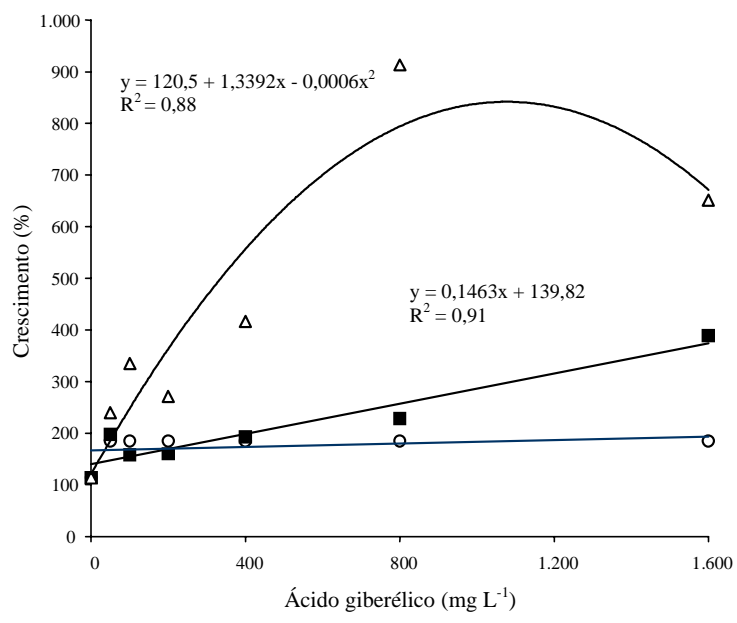

Figura 2. Porcentagem final de crescimento das plantas do porta-enxerto de macieira Marubakaido, após receberem diferentes concentrações de ácido giberélico em uma (o), duas ( $\mathbf{\square})$ ou três $(\Delta)$ aplicações. Embrapa-CPACT, Pelotas, RS. 
porcentagem de crescimento chegou a $867 \%$. Nas plantas-testemunhas, que não receberam tratamento, a porcentagem de crescimento observada, após 60 dias foi de $113 \%$. Estes resultados indicam que o maior número de aplicações e as doses mais elevadas desse regulador foram os tratamentos que proporcionaram maior crescimento das plantas.

De todos os reguladores de crescimento, a giberelina é o que apresenta os maiores efeitos no crescimento, quando aplicado em plantas intactas (Gianfagna, 1987; Peigang et al., 1994). Porém, uma única aplicação nem sempre é suficiente (Powell, 1987; Erez, 1995). Segundo Black et al. (1995), o desempenho dos reguladores de crescimento quando aplicados em plantas pode ser variável, dependendo da espécie a ser tratada. Sua ação é dependente de fatores, como absorção e transporte no vegetal, além da sensibilidade da planta a estes reguladores. As concentrações de $\mathrm{AG}_{3}$ utilizadas também podem variar dependendo da espécie. Modesto et al. (1996) estudaram os efeitos do $\mathrm{AG}_{3}$ no crescimento de Citrus limonia, de oito meses, em condições de viveiro, e observaram que o tratamento com $50 \mathrm{mg} \mathrm{L}^{-1}$, efetuado num total de quatro pulverizações semanais, promoveu um bom crescimento das plantas. Segundo Powell (1987) e Erez (1995), embora o $\mathrm{AG}_{3}$ melhore o crescimento das plantas, doses elevadas (acima de $100 \mathrm{mg} \mathrm{L}^{-1}$ ) e repetidas aplicações, são normalmente necessárias para se alcançar resultados satisfatórios. Por isso, o uso desta substância comercialmente torna os custos elevados. Porém, o desenvolvimento de novos agentes com maior capacidade de penetração nas plantas, poderá reduzir os custos, tornando $\mathrm{oAG}_{3}$ mais competitivo, podendo então ser utilizado em doses mais baixas e de forma mais eficiente.

As plantas mostraram que uma única aplicação não apresentou efeitos significativos sobre o crescimento dos entrenós (Figura 3). Nas plantas que receberam duas aplicações observou-se um crescimento linear no comprimento dos entrenós, com o aumento das concentrações de $\mathrm{AG}_{3}$. Por outro lado, o tratamento das plantas com três pulverizações, com concentrações mais elevadas de $\mathrm{AG}_{3}$, apresentaram os melhores resultados, proporcionando plantas com maior comprimento dos entrenós. Nas plantas deste tratamento, o comprimento dos entrenós aumentou até a concentração de $1.323 \mathrm{mg} \mathrm{L}^{-1}$ de $\mathrm{AG}_{3}$ (ponto de máxima eficiência calculada), quando estes atingiram $1,06 \mathrm{~cm}$ de comprimento.

Um dos efeitos mais pronunciados das giberelinas quando aplicadas em plantas é a promoção do alon- gamento dos entrenós. Embora ainda não sejam bem conhecidos os mecanismos de ação das giberelinas nas plantas, este regulador atua no controle de vários processos metabólicos das plantas, entre eles o alongamento e o crescimento. $\mathrm{O} \mathrm{AG}_{3}$ promove a divisão celular, estimulando as células na fase $G_{1}$ a passar mais rapidamente para a fase $\mathrm{S}$. Apesar de este mecanismo não ter sido ainda completamente elucidado, o aumento do número de células leva a um crescimento mais rápido, pelo fato de cada uma das células poder crescer. Outro importante efeito das giberelinas é que estas agem sobre o metabolismo dos glicídios envolvidos no fornecimento de energia às células e que podem contribuir para tornar o potencial osmótico celular mais negativo. Como resultado da diminuição do potencial osmótico, o fluxo de água ocorreria mais rapidamente para o interior da célula favorecendo assim sua expansão. Além desses efeitos, parece evidente também que as giberelinas aumentam a plasticidade da parede celular, controlando a ação de determinadas enzimas, que podem regular o fluxo de água nas células durante a expansão (Salisbury \& Ross, 1985; Hopkins, 1995; Huttly \& Phillips, 1995; Daykin et al., 1997).

Apesar do baixo coeficiente de determinação $\left(\mathrm{R}^{2}=0,42\right)$, o aumento na concentração de $\mathrm{AG}_{3}$ proporcionou um aumento da matéria seca da parte aérea das plantas (Figura 4). Segundo Benincasa (1988), o crescimento de uma planta pode ser estu-

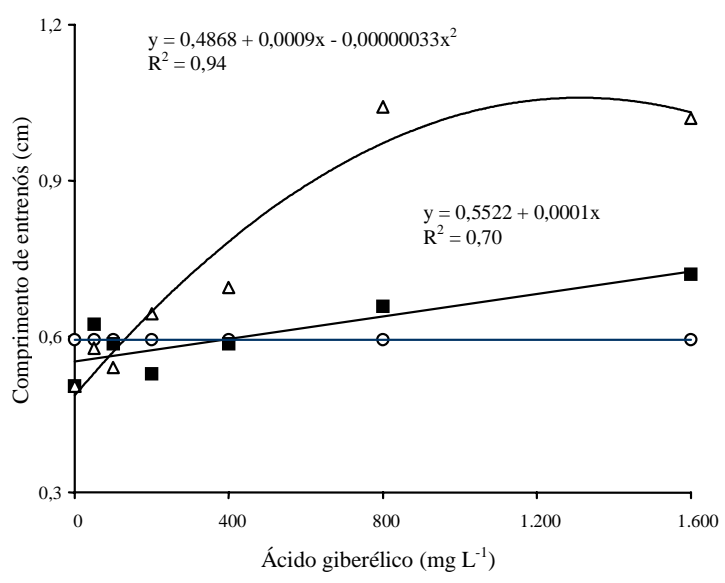

Figura 3. Efeito do número de aplicações $(\mathrm{O}, \boldsymbol{\square}$ e $\Delta$ uma, duas e três aplicações, respectivamente) de diferentes concentrações de ácido giberélico no comprimento dos entrenós das plantas do porta-enxerto de macieira Marubakaido. Embrapa-CPACT, Pelotas, RS. 


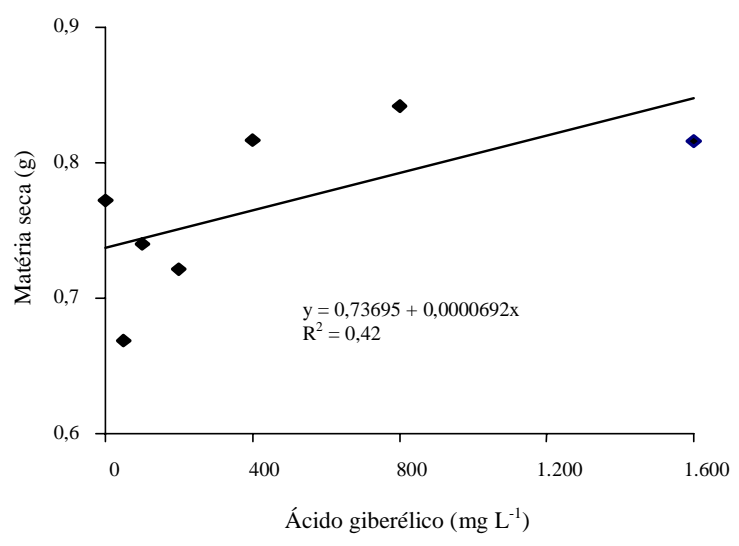

Figura 4. Matéria seca da parte aérea das plantas do porta-enxerto de macieira Marubakaido, em razão de diferentes concentrações de ácido giberélico. Embrapa-CPACT, Pelotas, RS.

dado através de medidas de diferentes tipos, como, por exemplo, a biomassa vegetal. A partir destes dados, pode-se estimar de forma mais precisa as causas do crescimento. $\mathrm{O}$ fato de terem sido observadas diferenças significativas entre os tratamentos em relação à matéria seca da parte aérea, poderia significar um maior acúmulo de fotossintetizados e uma maior absorção de minerais pelas plantas.

\section{Conclusões}

1. O uso do ácido giberélico $\left(\mathrm{AG}_{3}\right)$ em plantas do porta-enxerto de macieira 'Marubakaido' de um ano, oriundas da micropropagação, melhora o crescimento e o alongamento dos entrenós, além de aumentar a matéria seca da parte aérea das plantas.

2. Um número de pelo menos três aplicações, associado a concentrações elevadas $\left(800 \mathrm{mg} \mathrm{L}^{-1}\right)$, é necessário para melhorar a eficiência deste regulador sobre o crescimento das plantas.

\section{Referências}

BARBOSA, W.; DALL'ORTO, F. A. C.; OJIMA, M.; CAMPOS, S. A. F.; TOMBOLATO, A. F. C. Propagação vegetativa in vitro de cultivares de macieira. Bragantia, Campinas, v. 45, n. 1, p. 143-154, 1986.
BENINCASA, M. M. P. Análise de crescimento de plantas: noções básicas. Jaboticabal : FUNEP, 1988. 42 p.

BLACK, B. L.; PETRACEK, P. D.; BUKOVAC, M. J. The effect of temperature on uptake of NAA by Redchief 'delicious' apple leaves. American Society for Horticulture Science Journal, Alexandria, v. 120, n. 3, p. 441-445, 1995.

CHAMPAGNAT, P. Dormance des bourgeons chez les végétaux ligneux. In: CÔME, $D$. (Ed.). Les végétaux et le froid. Paris : Hérmann, 1992. p. 203-260.

DAYKIN, A.; SCOTT, I. M.; FRANCIS, D.; CAUSTON, D. R. Effects of gibberellin on the cellular dynamics of dwarf pea internode developpement. Planta, Berlin, v. 203, n. 4, p. 526-535, 1997.

DEBERGH, P. C. Micropropagation of woody species state of the art on in vitro aspects. Acta Horticulturae, Leuven, n. 227, p. 287-295, 1988.

DENARDI, F.; LEITE, G. B. Enxertia de mergulhia contínua: nova técnica de multiplicação rápida de porta-enxertos de macieira. Agropecuária Catarinense, Florianópolis, v. 9 , n. 4 , p. $16-18,1996$

EREZ, A. Means to compensate for insufficient chilling to improve bloom and leafing. Acta Horticulturae, Leuven, n. 395, p. 81-95, 1995.

GIANFAGNA, T. J. Natural and synthetic growth regulators and their use in horticultural and agronomic crops. In: DAVIES, P. J. (Ed.). Plant hormones and their role in plant growth and development. Dordrecht : Kluwer Academic, 1987. p. 614-635.

HOPKINS, W. G. Introduction to plant physiology. New York : J. Wiley, 1995. 464 p.

HUTTLY, A. K.; PHILLIPS, A. L. Gibberellin regulated plant genes. Physiologia Plantarum, Copenhagen, v. 95, n. 2 , p. $310-317,1995$.

HUYLENBROECK, J. M. van; DEBERGH, P. C. Physiological aspects in acclimatization of micropropagated plantlets. Plant Tissue Culture and Biotechnology, Rehovot, v. 2, n. 3, p. 136-141, 1996.

KAVANAGH，K. L.; LEE，D. H.; DREW，A. P.; MAYNARD, C. A. The effects of $\mathrm{GA}_{3}$ and organic solvents on acclimatization of tissue culture propagated black cherry (Prunus serotina Ehrh.) plantlets. Forest Science, Bethesda, v. 39, n. 4, p. 644-654, 1993.

METIVIER, J. R. Dormência e germinação. In: FERRI, M. G. (Ed.). Fisiologia vegetal 2. São Paulo : EPU, 1985. v. 2 , p. $343-392$. 
MODESTO, J. C.; RODRIGUES, J. D.; PINHO, S. Z. Efeito do ácido giberélico sobre o comprimento e diâmetro do caule de plantas de limão 'cravo' (Citrus limonia Osbeck). Scientia Agricola, Piracicaba, v. 53, n. 2/3, p. 332-337, 1996.

PEIGANG, X.; XIANG, S.; XIAOLIU,C.; XIN, P. G.; SHEN, X.; CHEN, X. L. A study on distribution of PP333 in young trees and its growth inhibition effect and inhibition-relieving with $\mathrm{GA}_{3}$. Journal of Shandong Agricultural University, Shandong, v. 25, n. 1, p. 1-8, 1994.

PEREIRA, J. E. S. Parada do crescimento de plantas do porta-enxerto de macieira Marubakaido (Malus prunifolia) durante a aclimatização: efeito de baixa temperatura e do ácido giberélico. Pelotas : UFPel, 1999. 93 p. Dissertação de Mestrado.

POWELL, L. E. The hormonal control of bud and seed dormancy in woody plants. In: DAVIES, P. J. (Ed.). Plant hormones and their role in plant growth and development. Dordrecht : Kluwer Academic, 1987. p. 539-552.

PREECE, J. E.; SUTTER, E. J. Acclimatization of micropropagated plants to the greenhouse and field. In: DEBERGH, P. C.; ZIMMERMAN, R. H. (Ed.). Micropropagation, technology and application. London : Kluver Academic, 1991. p. 71-93.

RIBAS, L. L. F. Micropropagação e estudo da parada de crescimento durante a aclimatização de mudas de macieira (Malus domestica Borkh.) cv. Gala, clone FZ. Curitiba : UFPR, 1991. 142 p. Dissertação de Mestrado.

RIBAS, L. L. F.; ZANETTE, F. Parada de crescimento de mudas de macieira da cv. Gala, clone FZ, durante a aclimatização em casa de vegetação. Revista Brasileira de Fruticultura, Cruz das Almas, v. 14, n. 2, p. 145-152, 1992.

SALISBURY, F. B.; ROSS, C. W. Growth responses to temperature. In: Plant physiology. Belmont : Wadsworth, 1985. p. 409-425.

SHALTOUT, A. D.; UNRATH, C. R. Effect of some growth regulators and nutritional compounds as substitutes for chilling of delicious apple leaf flower buds. American Society for Horticulture Science Journal, Alexandria, v. 108 , n. 6 , p. 898-901, 1983.

TOMLINSON, P. B.; OLDEMAN, R. A. A.; HALLÉ, F. La dormance des bourgeons. In: COLLOQUE INTERNATIONAL SUR L'ARBRE, 1985, Montpellier. Annales... Montpellier : Naturalia Monspeliense, 1985. p. 5-23.

ZIMMERMAN, R. H.; FORDHAM, I. Simplified method for rooting apple cultivars in vitro. American Society for Horticultural Science Journal, Alexandria, v. 110, n. 1, p. 34-38, 1985.

ZONTA, E. P.; MACHADO, A. A. SANEST: sistema de análise estatística para microcomputadores. Pelotas : UFPel-SEI, 1984. 138 p. 